\title{
Caracterização etiológica, epidemiológica e clínico-patológica da meningoencefalite por herpesvírus bovino em bovinos no Estado de Goiás ${ }^{1}$
}

\author{
Guilherme R. Blume², Lorena F. Silva², José R.J. Borges³, Luciano Nakazato ${ }^{4}$, \\ Juliano P. Terra ${ }^{5}$, Rogério E. Rabelo ${ }^{6}$, Valcinir A.S. Vulcani ${ }^{6}$ e Fabiano J.F. Sant'Ana ${ }^{7 *}$
}

ABSTRACT.- Blume G.R., Silva L.F., Borges J.R.J., Nakazato L., Terra J.P., Rabelo R.E., Vulcani V.A.S. \& Sant'Ana F.J.F. 2018. [Etiological, epidemiological, clinical and pathological characterization of meningoencephalitis in cattle by bovine herpesvirus in the State of Goiás, Brazil.] Caracterização etiológica, epidemiológica e clínico-patológica da meningoencefalite por herpesvírus bovino em bovinos no Estado de Goiás. Pesquisa Veterinária Brasileira 38(5):902-912. Laboratório de Diagnóstico Patológico Veterinário, Universidade de Brasília, Brasília, DF 70636-020, Brazil. E-mail: santanafjf@yahoo.com

Twenty six cases of bovine herpetic meningoencephalitis diagnosed from 2010-2016 in Goiás state, Brazil, were studied. Affected cattle were mainly 60-day to 18-month-old. There was no association of the disease with sex and seasonality. The disease was found in all five mesoregions with a higher prevalence in southern and central state of Goiás. Clinical signs more frequently observed included blindness, incoordination, circling, excessive salivation, and ataxia. Main gross findings in the brain were congestion with swelling and flattening of gyri, softening and yellow discoloration of cerebral cortex and hemorrhagic foci. In five cases no gross changes were observed in the brain and in four cases there is no information. The main histopathological changes were in the cortex of telencephalic lobes, especially the frontal and parietal; however less prominent and less frequently found lesions occurred in the thalamus, basal nuclei, midbrain, pons, medulla oblongata, cerebellum, and hippocampus. All cases presented lymphoplasmocytic meningoencephalitis and intranuclear basophilic inclusion bodies in astrocytes, less commonly in neurons. Other frequent lesions included segmental laminar neuronal necrosis (red neurons), spongiosis, swollen vascular endothelial nuclei, gliosis (focal and diffuse), hypertrophy of astrocytes, infiltration of gitter cells, congestion, and hemorrhage. Lesions less frequently observed were Alzheimer type II astrocytes, residual lesion and neuronophagia. The most frequently affected cortical layers by neuronal necrosis and edema were external and internal granular, molecular, and pyramidal cell layers. Gyri and sulci were equally affected. Of the 26 cases, in $2(7.69 \%)$ the DNA of BoHV-5 was amplified with samples fixed in $10 \%$ formalin and paraffin-embedded. DNA of BoHV-1 was identified in another case (3.84\%) where, positive to BoHV-1, fresh samples were used.

INDEX TERMS: Meningoencephalitis, cattle, bovine herpesvirus, neuropathology, distribution of lesions, viroses.

\footnotetext{
${ }^{1}$ Recebido em 23 de março de 2017.

Aceito para publicação em 15 de abril de 2017.

${ }^{2}$ Bolsista da CAPES, Programa de Pós-Graduação em Saúde Animal, área de concentração em Medicina Preventiva e Patologia Veterinária, Hospital Veterinário de Grandes Animais, Universidade de Brasília (UnB), Área Especial, Galpão 4, Granja do Torto, Brasília, DF 70636-020, Brasil.

${ }^{3}$ Hospital Veterinário de Grandes Animais, Universidade de Brasília (UnB), Área Especial, Galpão 4, Granja do Torto, Brasília, DF, 70636-020.

${ }^{4}$ Departamento de Clinica Médica Veterinária, Faculdade de Agronomia e Medicina Veterinária, Universidade Federal de Mato Grosso (UFMT), Av.
}

Fernando Corrêa da Costa 2367, Boa Esperança, Cuiabá, MT 78060-900, Brasil.

${ }^{5}$ Programa de Pós-Graduação em Ciência Animal, Universidade Federal de Goiás (UFG), Av. Esperança s/n, Chácaras de Recreio Samambaia, Goiânia, GO 74690-900, Brasil.

${ }^{6}$ Curso de Medicina Veterinária, Universidade Federal de Goiás (UFG), Regional Jataí, Rua Riachuelo 1530, Setor Samuel Graham, Jataí, G0 75804-020.

${ }^{7}$ Laboratório de Diagnóstico Patológico Veterinário (LDPV), Universidade de Brasília (UnB), Área Especial, Galpão 4, Granja do Torto, Brasília, DF 70636-020.*Autor para correspondência: santanafjf@yahoo.com 
RESUMO.- Foram estudados 26 casos de meningoencefalite por herpesvírus bovino (BoHV) diagnosticados entre 2010-2016, no Estado de Goiás (GO). A doença acometeu principalmente bovinos jovens, entre 60 dias a 18 meses de idade. Não houve associação entre os casos e o sexo dos bovinos e a sazonalidade. A doença foi observada em todas as cinco Mesorregiões do Estado, com uma frequência maior nas Mesorregiões Sul e Centro. Os sinais clínicos mais frequentemente observados incluíram cegueira, incoordenação, sialorreia e ataxia. As principais alterações macroscópicas observadas incluíram congestão com tumefação e achatamento das circunvoluções, amolecimento e amarelamento do córtex telencefálico e focos de hemorragia. Em cinco encéfalos, não foram observadas alterações macroscópicas e em quatro as alterações não foram informadas. As principais alterações histológicas ocorreram no córtex telencefálico, principalmente o córtex frontal e parietal, mas em alguns casos, lesões de menor intensidade foram também observadas no tálamo, núcleos basais, mesencéfalo, ponte, bulbo, cerebelo e hipocampo. Todos os casos apresentaram meningoencefalite linfoplasmocítica e corpúsculos de inclusão intranucleares basofílicos em astrócitos e, eventualmente, em neurônios. Outras lesões frequentes incluíram necrose neuronal laminar segmentar (neurônio vermelho), espongiose, tumefação do núcleo das células endoteliais, gliose focal ou difusa, hipertrofia de astrócitos, infiltração por células gitter, congestão e hemorragia. Lesões menos comuns incluíram astrócitos Alzheimer tipo II, lesão residual e neuronofagia. A necrose neuronal e o edema (espongiose) foram mais acentuados nas camadas granular externa, molecular, de células piramidais e granular interna dos telencéfalos. Tanto os giros quanto os sulcos foram afetados igualmente. Dos 26 casos, o DNA de BoHV-5 foi amplificado em dois $(7,69 \%)$ casos, enquanto que o de BoHV-1 foi identificado em um caso $(3,84 \%)$. Nos casos positivos para BoHV-5 foram usadas amostras fixadas em formol a $10 \%$ e incluídas em parafina e amostras congeladas foram utilizadas no caso positivo para BoHV-1.

TERMOS DE INDEXAÇÃO: Meningoencefalite, herpesvírus bovino, bovinos, neuropatologia, distribuição de lesões, viroses.

\section{INTRODUÇÃO}

Herpesvírus bovino (BoHV) tipo 1 (BoHV-1) e tipo 5 (BoHV-5) são vírus DNA, de cadeia dupla, envelopados, pertencentes a família Herpesviridae, subfamília Alphaherpesvirinae e gênero Varicellovirus (Roizmann et al. 1992, Gomes et al. 2002). Esses agentes estão associados a várias manifestações clínicas que incluem rinotraqueíte infecciosa bovina (IBR), vulvovaginite pustular, balanopostite pustular, abortos, conjuntivite, forma sistêmica neonatal e meningoencefalite (Franco \& Roehe 2007, Halfen \& Riet-Correa 2007). Geralmente, a forma neurológica é atribuída ao BoHV-5, enquanto que as demais manifestações costumam ser causadas pelo BoHV-1 (Ely et al. 1996, Silva et al. 2007, Arruda et al. 2010), porém ambos podem causar doença neurológica de difícil diferenciação clínica, sendo importante a aplicação de técnicas moleculares como a reação em cadeia de polimerase (PCR) (Lunardi et al. 2009). Em um trabalho realizado no Sul do Brasil, constatou-se que casos de meningoencefalite herpética bovina foram causados por ambos BoHV-1 e BoHV-5 (Rissi et al. 2008). Os dois vírus apresentam características biológicas, moleculares e estruturais muito similares, porém possuem algumas diferenças genéticas e imunogênicas que estão relacionadas às particularidades de cada tipo viral em relação à sua patogenicidade e epidemiologia (Franco \& Roehe 2007).

A meningoencefalite tem sido observada em várias regiões do mundo e, no Brasil, surtos de rinotraqueíte, vulvovaginite e balanopostite são diagnosticados em várias regiões do país. A meningoencefalite associada ao BoHV-5 é uma doença infecto-contagiosa que afeta principalmente bovinos jovens e têm sido reportada em vários estados brasileiros, como Rio Grande do Sul (Riet-Correa et al. 1989, Sanches et al. 2000, Elias et al. 2004, Rissi et al. 2006, Silva et al. 2007, Rissi \& Barros 2013), Paraná (Claus et al. 2007, Lunardi et al. 2009, Massitel et al. 2016), Rio de Janeiro, Minas Gerais (Gomes et al. 2002, Claus et al. 2007, Franco \& Roehe 2007, Aquino Neto et al. 2009, Oliveira et al. 2016), Mato Grosso (Colodel et al. 2002, Claus et al. 2007, Arruda et al. 2010), Pernambuco (Oliveira et al. 2014), Paraíba, Rio Grande do Norte (Galiza et al. 2010), Pará (Riet-Correa et al. 2006), São Paulo (Claus et al. 2007, Ferrari et al. 2007, Cunha et al. 2009) e Mato Grosso do Sul (Salvador et al. 1998, Gomes et al. 2002, Lemos 2005, Claus et al. 2007, Silva et al. 2007). Em Goiás, a doença é pouco estudada (De Paula et al. 2005, Silva 2014) e dois surtos neurológicos da doença foram diagnosticados na região Sudoeste do Estado (Freitas Neto et al. 2010). No Rio Grande do Sul, a meningoencefalite por BoHV-5 é considerada a segunda causa mais frequente de infecção viral do sistema nervoso central de bovinos, perdendo apenas para a raiva (Sanches et al. 2000) e no Centro-Oeste é uma das doenças mais importantes em bovinos (Colodel et al. 2002). No Brasil, a doença neurológica tem sido observada sob a forma de surtos ou de casos individuais, de forma espontânea ou experimental, apresentando baixa morbidade, mortalidade e alta letalidade (Salvador et al. 1998, Meyer et al. 2001, Colodel et al. 2002, Elias et al. 2004, De Paula et al. 2005, Riet-Correa et al. 2006, Rissi et al. 2006, Lunardi et al. 2009, Freitas Neto et al. 2010, Cagnini et al. 2015) e não apresenta sazonalidade (Salvador et al. 1998, Elias et al. 2004, Barros et al. 2006).

Diante da importância que essa enfermidade possui em várias regiões do Brasil e da escassez de informações relacionadas à forma neurológica da infecção no Estado de Goiás, importante produtor nacional de carne e leite, o presente trabalho tem como objetivo descrever os achados epidemiológicos, moleculares e clínico-patológicos, bem como a distribuição das alterações no encéfalo, de 26 casos naturais de meningoencefalite herpética bovina diagnosticados nesse estado.

\section{MATERIAL E MÉTODOS}

Foi realizado um estudo retrospectivo de 26 casos naturais de meningoencefalite por BoHV entre março de 2010 a maio de 2016 nos arquivos do Laboratórios de Patologia Veterinária (LPV) da Universidade Federal de Goiás (UFG), Regional Jataí (RJ), e no Laboratório de Diagnóstico Patológico Veterinário (LDPV) da Universidade de Brasília (UnB) entre julho de 2015 a maio de 2016. Grande parte $(23 / 26,88,46 \%)$ das amostras utilizadas no estudo foi de encéfalos fornecidos gentilmente pelo Laboratório de Análise e Diagnóstico Veterinário (LABVET) da Agência Goiana de Defesa Agropecuária (AGRODEFESA), em Goiânia/GO. Foram revisados os protocolos de necropsia e de histopatologia de bovinos do LPV/UFG/RJ e do LDPV/UnB. Partes desses casos foram recebidas 
sem determinação exata do tempo de fixação em formol a 10\%. Os outros casos (3/26 ou 11,53\%) foram obtidos de necropsias realizadas pela equipe do LPV/UFG/RJ. Todas as amostras são de bovinos que apresentaram resultado negativo na imunofluorescência direta e na prova biológica para raiva.

Após a necropsia, as amostras de encéfalo foram coletadas e fixadas em formol tamponado a 10\%, permanecendo de dias até meses no fixador. Adicionalmente foram colhidos e fixados no mesmo fixador, os complexos gânglio de Gasser, rete mirabile carotídea e hipófise (GRH) de dez casos. Após a fixação, realizaram-se cortes transversais no encéfalo com intervalos de 1-2 cm para avaliação macroscópica. As seguintes seções foram preparadas para avaliação microscópica: cerebelo, bulbo na altura do óbex, ponte com pedúnculos cerebelares, mesencéfalo na altura dos colículos rostrais, tálamo, núcleos basais, hipocampo, telencéfalos frontal, parietal e occipital e o monobloco do complexo GRH (Barros \& Marques 2003). Todos os fragmentos foram processados rotineiramente para histologia, incluídos em parafina e corados pela hematoxilina-eosina (HE).

Microscopicamente, as lesões foram avaliadas qualitativa e quantitativamente. No primeiro caso, foram anotados a intensidade de necrose neuronal, edema, os tipos celulares predominantes nos manguitos perivasculares, o tipo de reação glial (gliose focal/difusa), congestão, hemorragia, separação entre as substâncias branca e cinzenta, lesão residual, neuronofagia, infiltração por células gitter e tumefação de núcleos de células endoteliais. As lesões encontradas foram classificadas quanto à intensidade em ausente (0), leve (1), moderada (2) ou acentuada (3), sendo leve com cerca de $0-25 \%$, moderado $25-50 \%$ e acentuado mais de $50 \%$ do tecido afetado. Os manguitos também foram classificados com relação ao número de camadas de células inflamatórias em leve (até 2 camadas), moderado (de 3 a 5 camadas) e acentuado (com mais de 6 camadas). Foi avaliada também a distribuição de necrose neuronal e edema nas seis camadas de neurônios (molecular, granular externa, células piramidais, granular interna, ganglionar e de células polimórficas) dos telencéfalos frontal, parietal e occipital.

Para a determinação do tipo do herpesvírus bovino (BoHV-1 ou BoHV-5) envolvido nos casos, foram realizadas análises moleculares, através da reação em cadeia da polimerase (PCR) para extração de DNA das amostras de encéfalo (telencéfalo e tronco encefálico) congeladas a $-80^{\circ} \mathrm{C}$ em um caso e dos blocos de parafina dos outros 25 casos (Claus et al. 2005, Arruda et al. 2010). A reação de PCR foi realizada conforme descrito por Claus et al (2005) e a leitura foi realizada por eletroforese em gel de agarose a $2 \%$ corado com GelRed (Biotium) em transluminador (UV-300nm). Como controle negativo foi utilizado agua ultrapura. DNA de isolados de BHV-1 e BHV-5 foram gentilmente cedidos pelo Prof. Rudi Weiblein (UFSM) e foram utilizados como controles postivos.

\section{RESULTADOS}

Os principais dados epidemiológicos dos casos de meningoencefalite herpética observados encontram-se no Quadro 1. A maioria $(22 / 26,84,61 \%)$ dos casos diagnosticados ocorreu em bovinos

Quadro 1. Dados epidemiológicos de 26 casos de meningoencefalite herpética diagnosticados em bovinos no Estado de Goiás (2010-2016)

\begin{tabular}{|c|c|c|c|c|c|}
\hline Caso & Município & Raça & Idade & Sexo & Época do ano \\
\hline 1 & Mineiros & Nelore & 15 meses & Fêmea & Abril \\
\hline 2 & Serranópolis & Nelore/Simental & 8 meses & Macho & Agosto \\
\hline 3 & Pontalina & Nelore & 18 meses & Macho & Abril \\
\hline 4 & Aragarças & Nelore & 2 anos & Macho & Julho \\
\hline 5 & Simolândia & SRD & 16 meses & Macho & Agosto \\
\hline 6 & Mundo Novo & Nelore & 22 meses & Macho & Setembro \\
\hline 7 & Baliza & SRD & 2 anos & Fêmea & Novembro \\
\hline 8 & Jataí & Nelore & 2 anos & Macho & Novembro \\
\hline 9 & Itarumã & Nelore & 10 anos & Fêmea & Novembro \\
\hline 10 & Nova América & Guzerá & 8 anos & Fêmea & Dezembro \\
\hline 11 & Ceres & SRD & 3 meses & Fêmea & Dezembro \\
\hline 12 & Ceres & SRD & 3 meses & Fêmea & Dezembro \\
\hline 13 & Goiânia & 3/4 Girolanda & 7 anos & Fêmea & Março \\
\hline 14 & Aparecida do Rio Doce & Nelore & 15 meses & Macho & Abril \\
\hline 15 & Inaciolândia & Nelore & 15 meses & Macho & Maio \\
\hline 16 & Orizona & Nelore & 5 meses & Fêmea & Maio \\
\hline 17 & n.i. & n.i & Adulto & n.i. & Maio \\
\hline 18 & Pontalina & Nelore/Holandês & 7 meses & Macho & Junho \\
\hline 19 & Israelândia & Nelore & 20 meses & Macho & Novembro \\
\hline 20 & Flores de Goiás & Nelore & 15 meses & Macho & Abril \\
\hline 21 & Posse & Nelore & 12 meses & Macho & Fevereiro \\
\hline 22 & Rubiataba & Nelore & 3 meses & Fêmea & Agosto \\
\hline 23 & Goiatuba & Mestiço & 2 anos & n.i. & Setembro \\
\hline 24 & Rubiataba & Girolando & 18 meses & Fêmea & Agosto \\
\hline 25 & Minaçu & Nelore & 2 anos & Fêmea & Maio \\
\hline 26 & Bonópolis & $1 / 2$ Angus & 9 meses & Macho & Julho \\
\hline
\end{tabular}

SRD = sem raça definida, n.i. = não informado. 
de dois anos de idade ou menos. Um animal foi informado como adulto, sem descriminar precisamente a idade. Foi observada predominância da raça Nelore, sendo mais da metade dos bovinos (14/26, 53,84\%). Não houve preferência por sexo, sendo acometidos 13 machos, 11 fêmeas e dois animais sem sexo informado. Não se observou sazonalidade na ocorrência da doença.

A distribuição geográfica foi uniforme e está representada no Quadro 1 e Figura 1. Houve concentração maior de casos nas Mesorregiões Sul (10/26, 38,46\%) e Centro (7/26, 26,92\%). Não foi possível avaliar a evolução, morbidade, mortalidade e letalidade da doença devido à indisponibilidade dos dados necessários para essas avaliações nas fichas.

0 Quadro 2 mostra a frequência de sinais clínicos descritos nos 26 casos relatados. Os principais sinais observados foram cegueira, incoordenação, sialorreia e ataxia.

Os principais achados macroscópicos descritos no encéfalo consistiam de congestão $(15 / 26,57,69 \%)$ e tumefação com achatamento das circunvoluções cerebrais (10/26, 38,46\%). Em oito casos $(30,76 \%)$, foram observadas áreas de amolecimento ou amarelamento telencefálico, sendo um com depressão acentuada bilateral e simétrica do córtex frontal (Fig.2), características de malacia. Adicionalmente, focos de hemorragia foram visualizados em sete casos $(26,92 \%)$ afetando o telencéfalo e o cerebelo. Cinco casos $(19,23 \%)$ não apresentaram alterações macroscópicas e em quatro $(15,38 \%)$ as alterações não foram informadas. Três casos (11,53\%) apresentaram linhas com separação entre as substâncias branca e cinzenta (Fig.3).

A Figura 4 mostra que as principais alterações microscópicas predominaram no córtex frontal e parietal, com menor intensidade nas outras seções avaliadas do encéfalo. Em nenhum dos casos foram observadas alterações histológicas no complexo GRH. Todos os animais apresentaram corpúsculos de inclusão intranucleares basofílicos em astrócitos (Fig.5) e, eventualmente,

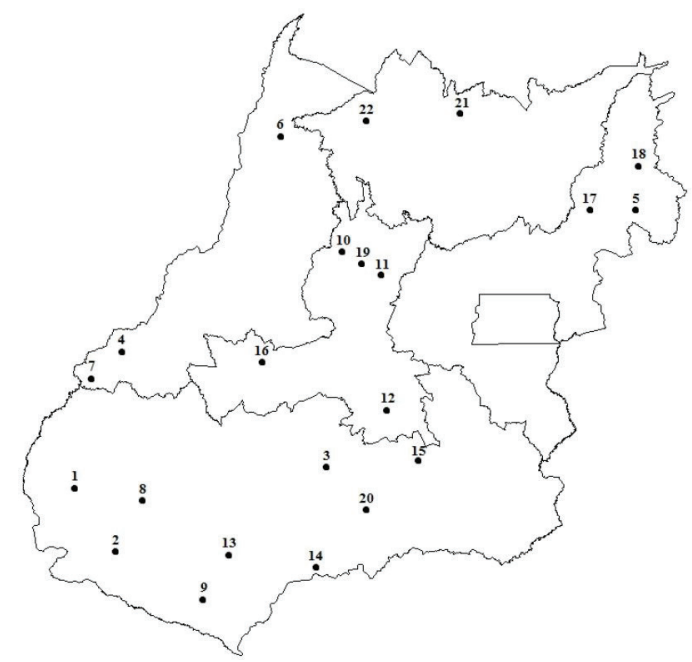

Fig.1. Mapa de Goiás com a localização dos municípios onde ocorreram os casos de meningoencefalite por herpesvírus bovino (BoHV) descritos neste estudo: Mineiros (1), Serranópolis (2), Pontalina (3), Aragarças (4), Simolândia (5), Mundo Novo (6) Baliza (7), Jataí (8), Itarumã (9), Nova América (10), Ceres (11), Goiânia (12), Aparecida do Rio Doce (13), Inaciolândia (14), Orizona (15), Israelândia (16), Flores de Goiás (17), Posse (18), Rubiataba (19), Goiatuba (20), Minaçu (21), Bonópolis (22). em neurônios. As principais alterações microscópicas incluíam meningoencefalite linfoplasmocítica (Fig.6), ocasionalmente com macrófagos e neutrófilos, tumefação do núcleo de células endoteliais dos vasos, necrose neuronal segmentar e laminar

Quadro 2. Frequência de sinais clínicos em 26 casos de meningoencefalite herpética em bovinos diagnosticados no Estado de Goiás (2010-2016)

\begin{tabular}{|c|c|}
\hline Sinais clínicos & Frequência \\
\hline Cegueira & $19(73,07 \%)$ \\
\hline Incoordenação & $17(65,38 \%)$ \\
\hline Sialorreia & $12(46,15 \%)$ \\
\hline Ataxia & $10(38,46 \%)$ \\
\hline Hiporexia/Anorexia & $8(30,76 \%)$ \\
\hline Andar em círculos & $7(26,92 \%)$ \\
\hline Paralisia flácida dos membros pélvicos & $6(23,07 \%)$ \\
\hline Apetite anômalo & $6(23,07 \%)$ \\
\hline Apatia/Depressão & $6(23,07 \%)$ \\
\hline Espasmos musculares & $6(23,07 \%)$ \\
\hline Tremores musculares & $5(19,23 \%)$ \\
\hline Agressividade & $4(15,38 \%)$ \\
\hline Movimentos de pedalagem & $4(15,38 \%)$ \\
\hline Dismetria & $4(15,38 \%)$ \\
\hline Decúbito & $4(15,38 \%)$ \\
\hline Desidratação & $3(11,53 \%)$ \\
\hline Tetania & $3(11,53 \%)$ \\
\hline Nistagmo & $2(7,69 \%)$ \\
\hline Opistótono & $2(7,69 \%)$ \\
\hline Secreção nasal/Dispneia & $2(7,69 \%)$ \\
\hline Midríase & $2(7,69 \%)$ \\
\hline Afastamento do rebanho & $2(7,69 \%)$ \\
\hline Bruxismo & $1(3,84 \%)$ \\
\hline Fotofobia & $1(3,84 \%)$ \\
\hline Febre & $1(3,84 \%)$ \\
\hline Convulsão & $1(3,84 \%)$ \\
\hline Priaprismo & $1(3,84 \%)$ \\
\hline Tenesmo & $1(3,84 \%)$ \\
\hline
\end{tabular}

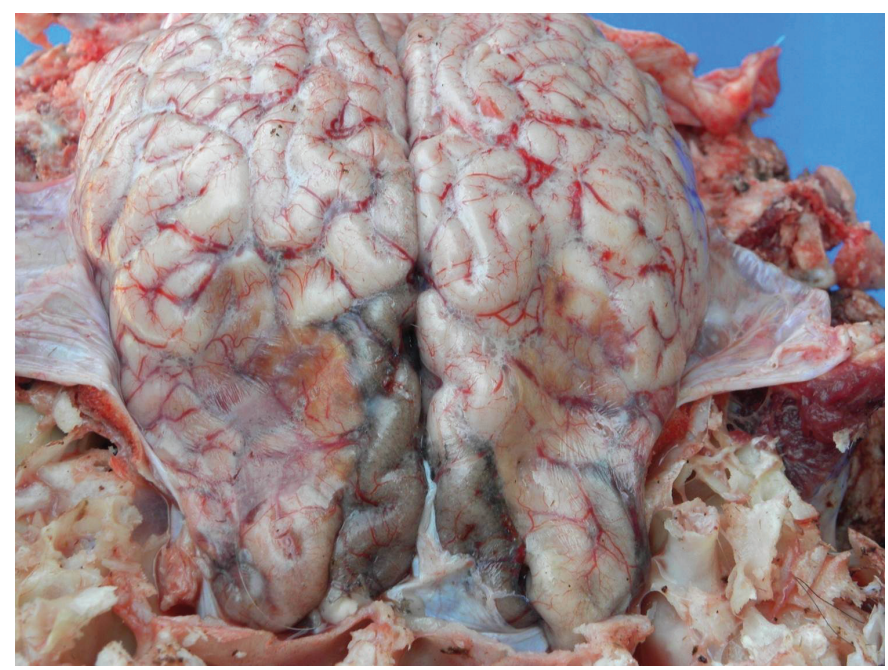

Fig.2. Encéfalo de um bovino com meningoencefalite herpética. Córtex frontal apresenta área focalmente extensa bilateral simétrica de malácia. 


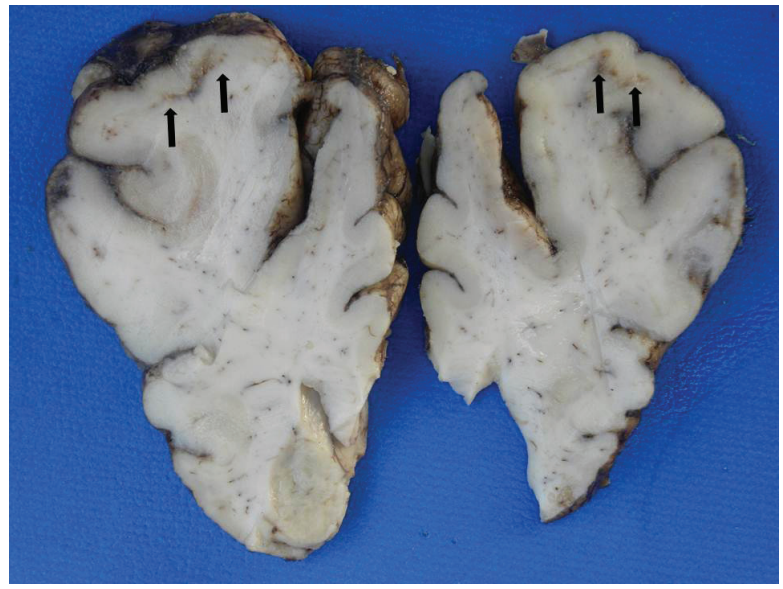

Fig.3. Encéfalo de um bovino com meningoencefalite herpética. Linhas de separação entre a substância cinzenta a branca do telencéfalo frontal (setas).

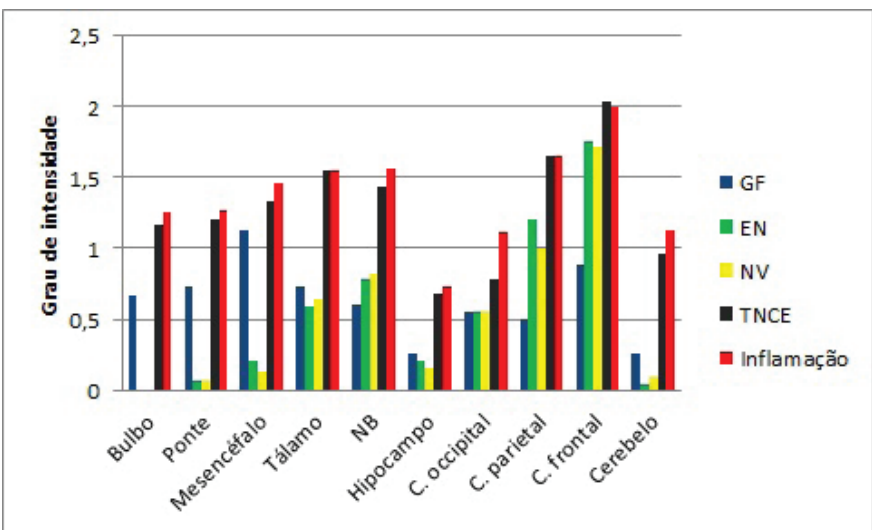

Fig.4. Distribuição e intensidade das lesões histológicas no encéfalo em 26 casos de meningoencefalite herpética em bovinos. Graus de intensidade de 0 (ausência de lesão) a 3 (lesão acentuada) foram atribuídos. $\mathrm{C}=$ córtex, $\mathrm{NB}=$ núcleos basais, $\mathrm{GF}=$ gliose focal, $\mathrm{EN}$ = edema de neurópilo, $\mathrm{NV}=$ neurônios vermelhos (necrose neuronal), TNCE = tumefação de núcleos de células endoteliais.

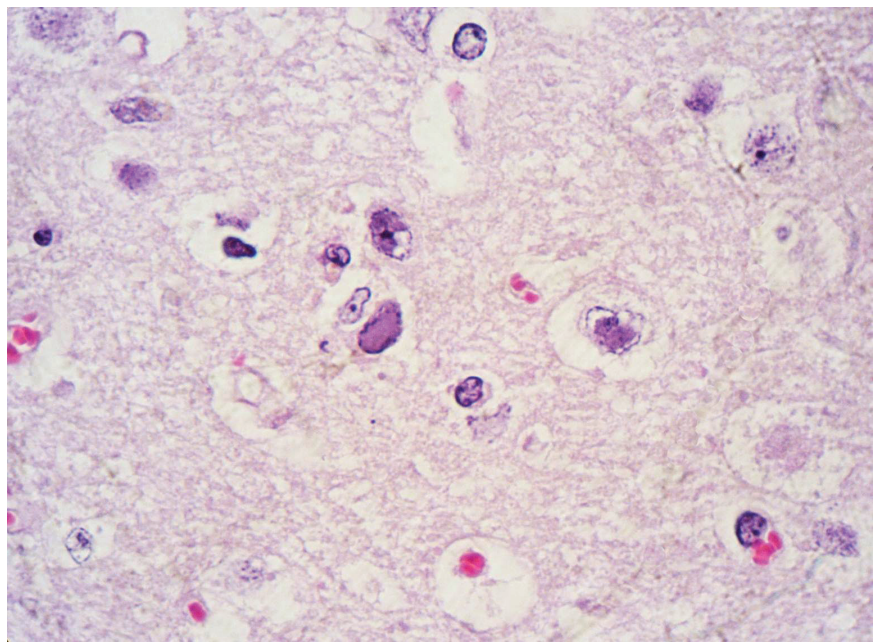

Fig.5. Aspecto histológico do córtex telencefálico de um bovino com meningoencefalite herpética mostrando corpúsculos de inclusão intranucleares basofílicos em astrócitos. HE, obj.40x.
(Fig.7), edema (espongiose) perineuronal, perivascular e no neurópilo (Fig.8), gliose focal, hipertrofia de astrócitos, congestão e hemorragia. Ocasionalmente eram observados grupos de dois ou três astrócitos com núcleos vesiculosos e tumefeitos, morfologia compatível com astrócitos Alzheimer tipo II (Fig.9); nos casos com lesões mais avançadas, numerosos macrófagos tumefeitos com citoplasma espumoso (células gitter) eram observados principalmente no espaço perivascular e no neurópilo e sob as leptomeninges (Fig.10). Os neurônios necróticos eram caracterizados por encarquilhamento e hipereosinofilia citoplasmáticas, picnose nuclear sem evidenciação nucleolar e desaparecimento da substância de Nissl. A necrose neuronal ocorreu tanto nos topos quanto nos sulcos das circunvoluções cerebrais. 0 edema na substância cinzenta era acentuado e, em três casos, deixava o neurópilo com aspecto esponjoso, separando a substância cinzenta da branca ou as camadas de neurônios da substância cinzenta (Fig.11). Lesão residual, caracterizada por áreas cavitárias com perda dos componentes neuroectodérmicos, associado à preservação de estruturas vasculares e células gitter (Fig.12), além de gliose difusa

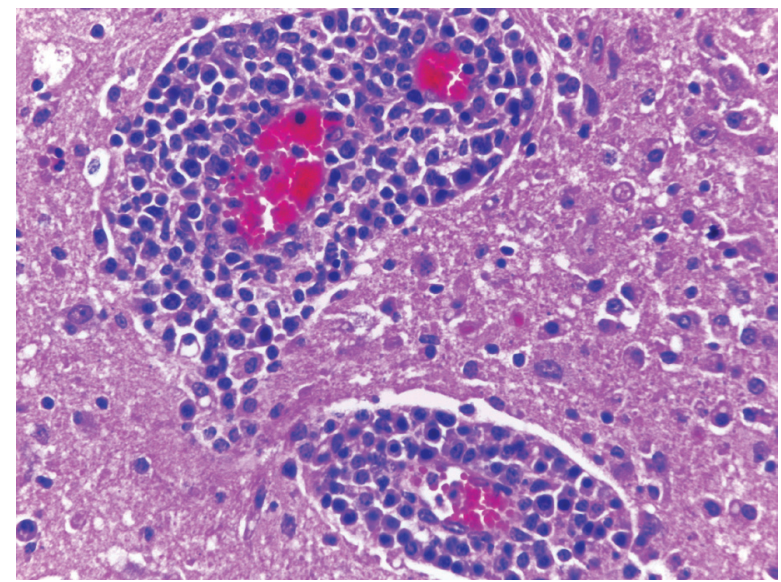

Fig.6. Aspecto histológico do córtex telencefálico de um bovino com meningoencefalite herpética mostrando manguitos perivasculares com linfócitos, plasmócitos e macrófagos. HE, obj.40x.

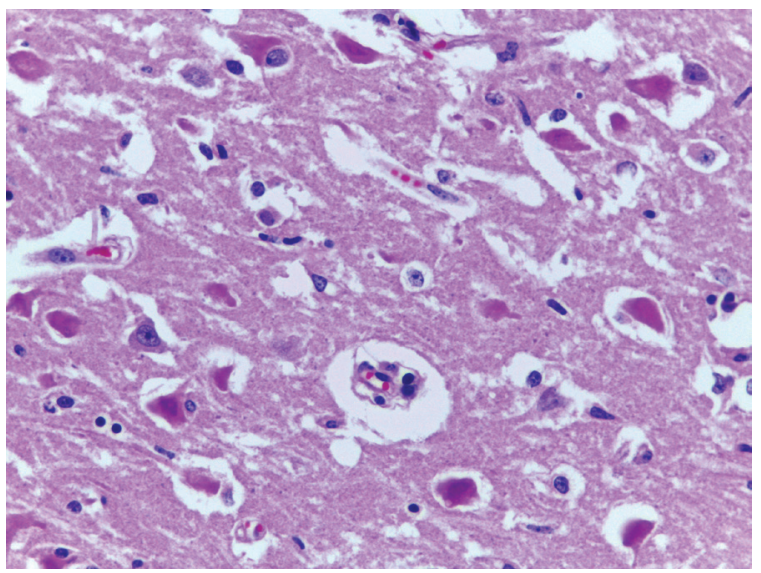

Fig.7. Aspecto histológico do córtex telencefálico de um bovino com meningoencefalite herpética mostrando necrose neuronal. O citoplasma dos neurônios necróticos está encarquilhado e fortemente eosinofílico (neurônios vermelhos). Nota-se ainda edema perineuronal e perivascular. HE, obj.40x. 


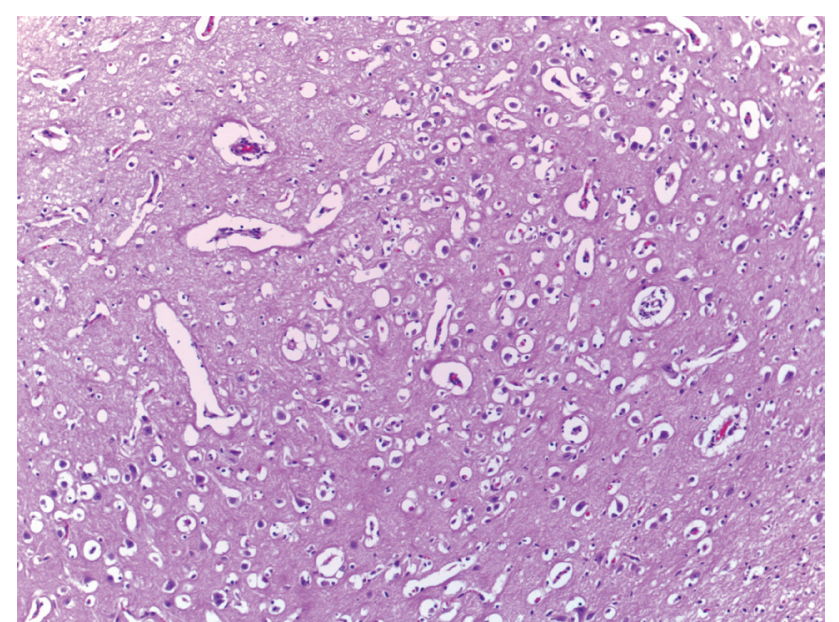

Fig.8. Aspecto histológico do córtex telencefálico de um bovino com meningoencefalite herpética mostrando vacuolização perineuronal, perivascular e no neurópilo (edema). HE, obj.10x.

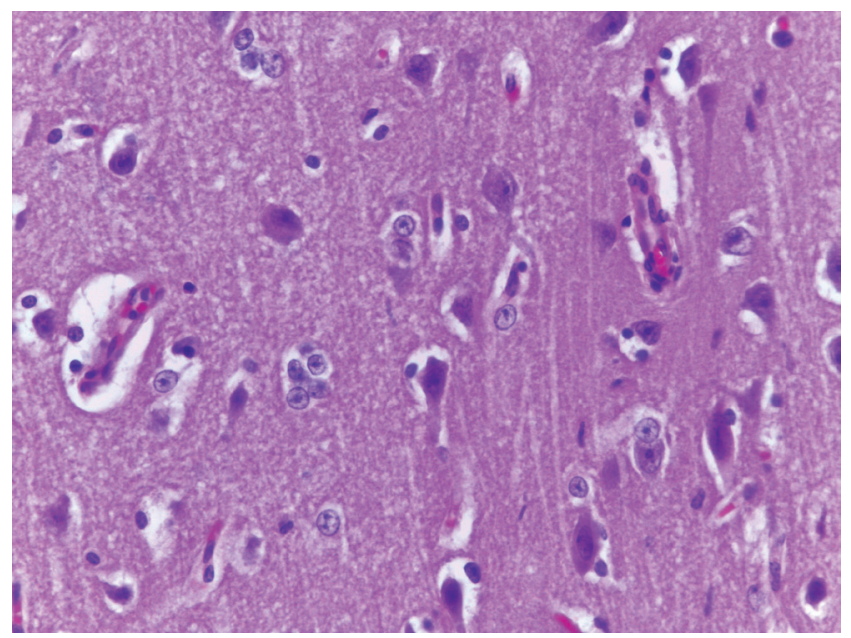

Fig.9. Aspecto histológico do córtex telencefálico de um bovino com meningoencefalite herpética mostrando grupos de dois a quatro astrócitos com núcleos vesiculosos e tumefeitos (astrócitos Alzheimer tipo II). HE, obj.40x.

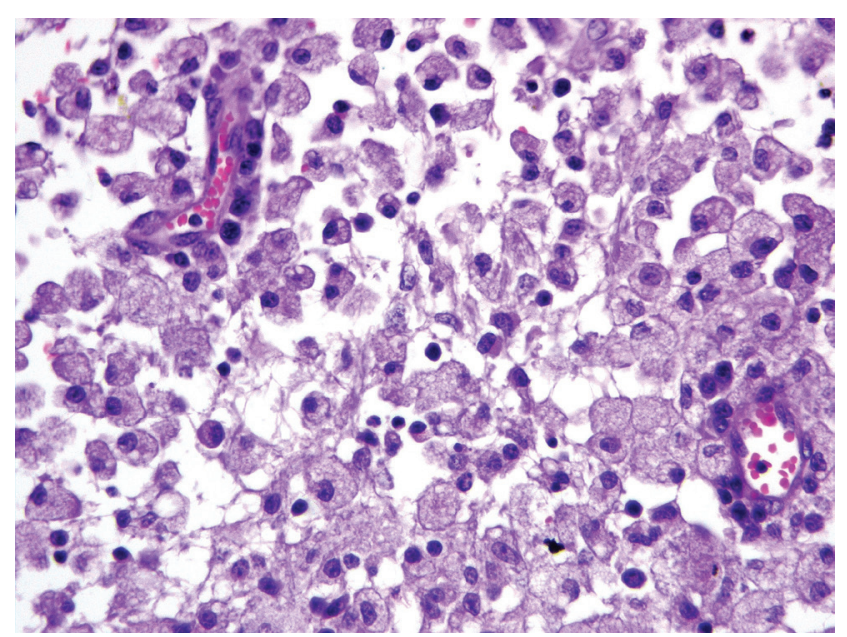

Fig.10. Aspecto histológico do córtex telencefálico de um bovino com meningoencefalite herpética avançada mostrando infiltração de macrófagos tumefeitos com citoplasma espumoso (células gitter), caracterizando malacia. HE, obj.40x.

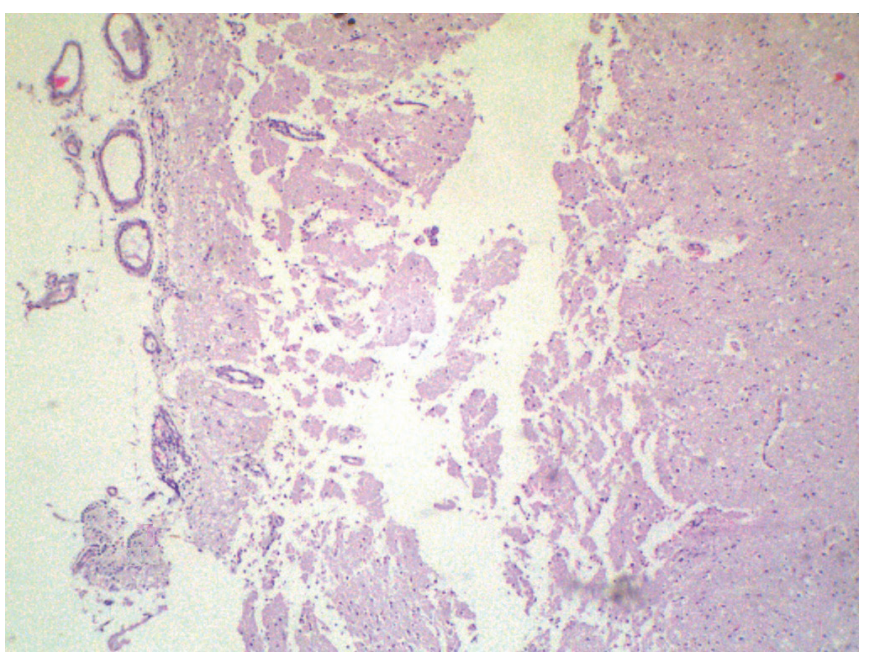

Fig.11. Aspecto histológico do córtex telencefálico de um bovino com meningoencefalite herpética mostrando linhas de separação entre camadas de neurônios da substância cinzenta devido ao edema acentuado. HE, obj.10x.

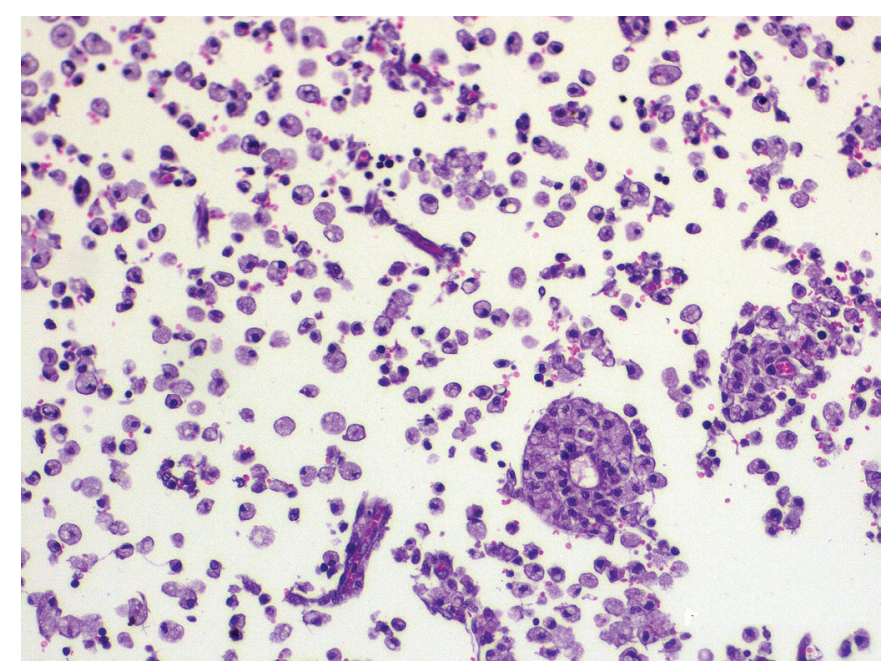

Fig.12. Aspecto histológico do córtex telencefálico de um bovino com meningoencefalite herpética com lesão residual, caracterizada por perda dos componentes neuroectodérmicos com preservação de estruturas vasculares e numerosas células gitter. HE, obj.20x.

e neuronofagia foram observadas com pouca frequência. A distribuição da necrose neuronal e do edema nas lâminas de neurônios do córtex frontal, parietal e occipital encontra-se ilustrada nas Figuras 13 e 14, respectivamente. As principais regiões afetadas foram as camadas granular externa, molecular, de células piramidais e granular interna.

Das 26 amostras, o DNA de BoHV-5 foi amplificado em $7,69 \%(2 / 26)$ e o BoHV-1 em 3,84\% (1/26), totalizando $11,53 \%$ de positividade ao BoHV. Desses casos, em dois, utilizou-se amostras fixadas em formol a $10 \%$ e incluídas em parafina e amostras congeladas de encéfalo foram usadas em apenas um caso. 


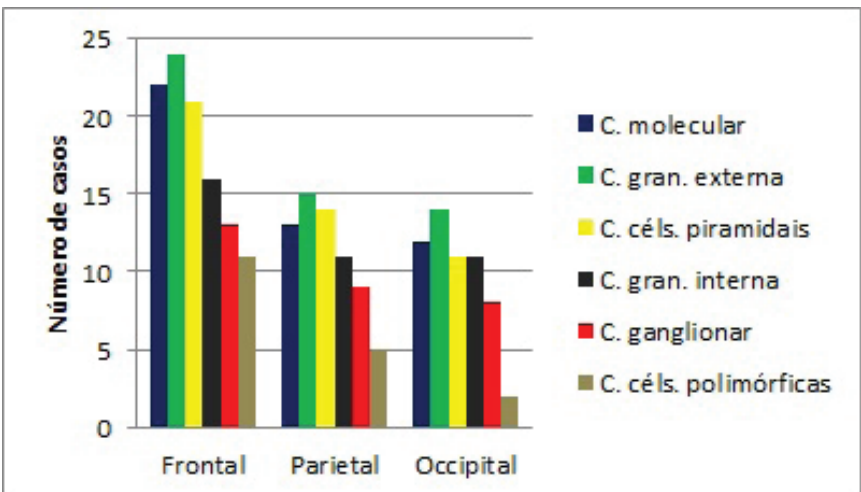

Fig.13. Distribuição de necrose neuronal (neurônios vermelhos) nas lâminas de neurônios do córtex frontal, parietal e occipital em 26 casos de meningoencefalite herpética em bovinos. $\mathrm{C}=$ camada, gran.$=$ granular, céls $=$ células.

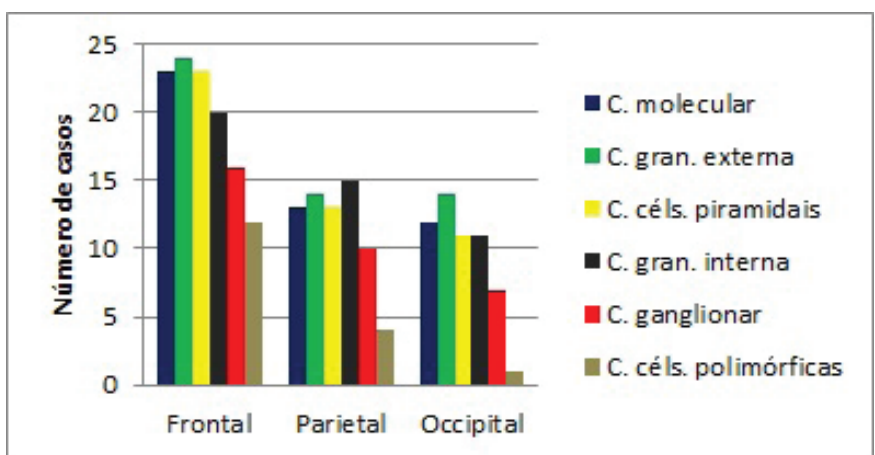

Fig.14. Distribuição de edema no córtex frontal, parietal e occipital em 26 casos de meningoencefalite herpética em bovinos. $\mathrm{C}=$ camada, gran. granular, céls $=$ células .

\section{DISCUSSÃO}

Dados epidemiológicos semelhantes aos observados neste estudo foram mencionados por outros autores, indicando que a meningoencefalite herpética pode ocorrer na forma de surtos (Lunardi et al. 2009, Freitas Neto et al. 2010, Oliveira et al. 2014) ou como casos isolados (De Paula et al. 2005, Riet-Correa et al. 2006, Cunha et al. 2009, Galiza et al. 2010). Essa neuropatia acomete principalmente bovinos jovens, entre 60 dias e 18 meses de idade (Rissi et al. 2007, Massitel et al. 2016), semelhante a faixa etária dos animais acometidos no presente estudo, em que 22 dos $26(84,61 \%)$ casos diagnosticados apresentavam dois anos de idade ou menos. Porém, foram observados três casos em bovinos com idade entre 7-10 anos e em um animal adulto, o que reforça a importância de incluir a meningoencefalite por BoHV no diagnóstico diferencial de neuropatias centrais em bovinos adultos.

A doença é comumente relatada em bovinos de corte, afetando taurinos (Elias et al. 2004, Lunardi et al. 2009) e zebuínos (Salvador et al. 1998, Colodel et al. 2002, Pedraza et al. 2010). 0 fato de um maior número de bovinos Nelore nesse estudo serem afetados deve-se provavelmente a predominância dessa raça no Estado de Goiás. Fato semelhante ocorreu em casos descritos no Paraná (Massitel et al. 2016) e em Mato Grosso (Colodel et al. 2002). Alguns autores relataram casos da doença em animais manejados em sistema de criação extensivo (Salvador et al. 1998, Colodel et al. 2002, Elias et al. 2004), semi-intensivo (Barros et al. 2006, Aquino Neto et al. 2009) e intensivo (Elias et al. 2004, Cunha et al. 2009, Lunardi et al. 2009), submetidos a situações de estresse, principalmente desmama precoce (Rissi et al. 2006).

O Estado de Goiás tem cinco Mesorregiões (Norte, Noroeste, Leste, Centro e Sul). No presente estudo, casos de meningoencefalite herpética foram diagnosticados em todas as Mesorregiões, com uma concentração maior de casos na Sul $(10 / 26,38,46 \%)$ e Centro $(7 / 26,26,92 \%)$, o que demonstra a importância epidemiológica da doença em todo o Estado. É possível que a maior concentração de casos nessas duas regiões supracitadas seja atribuída a proximidade dos municípios com dois laboratórios de diagnóstico que receberam as amostras (LPV/UFG/RJ e LABVET). Dos poucos casos descritos previamente na literatura dessa infecção neurológica em Goiás, dois surtos ocorreram no Sudoeste (Freitas Neto et al. 2010) e em outros casos não houve citação da região afetada (De Paula et al. 2005, Silva 2014).

Neste estudo, notou-se que a doença ocorreu em praticamente todos os meses do ano, não apresentando sazonalidade, semelhante ao observado por outros autores em outras regiões do Brasil (Salvador et al. 1998, Elias et al. 2004, Lemos 2005, Rissi et al. 2006, Massitel et al. 2016). Também não houve preferência por sexo, semelhante aos achados de outros autores (Ely et al. 1996, Elias et al. 2004, Rissi et al. 2006), porém diferente de outros estudos que detectaram maior prevalência em machos (Lemos 2005, Lunardi et al. 2009, Pedraza et al. 2010, Massitel et al. 2016).

Os sinais clínicos apresentados pelos bovinos deste estudo foram semelhantes aos relatados em outras descrições de meningoencefalite herpética bovina (Ely et al. 1996, Colodel et al. 2002, Elias et al. 2004, Lemos 2005, Rissi \& Barros 2013). Os principais sinais observados foram cegueira, incoordenação, sialorreia e ataxia. A cegueira e sialorreia indicam lesões em porções rostrais do telencéfalo, principalmente do córtex frontal e a alta taxa de replicação viral em mucosa oral, encontrados frequentemente em animais onde a viremia e transmissão ocorreram via bulbo olfatório (Meyer et al. 2001, Vogel et al. 2003, Rissi et al. 2006). A ataxia e incoordenação podem ser explicadas pelo edema e compressão cerebelar. A diversidade de sinais clínicos apresentados por animais doentes se deve à localização variável do vírus, que pode causar lesões desde o telencéfalos frontal até a medula espinhal (Elias et al. 2004). Alguns autores citam que sinais clínicos de disfunção de nervos cranianos e de tronco encefálico são observados em casos agudos e crônicos da doença, respectivamente (Rissi et al. 2006, Lunardi et al. 2009). Bovinos infectados pelos vírus podem não apresentar sinais clínicos da enfermidade e representar importante fonte de disseminação para outros bovinos susceptíveis do rebanho (Isernhagen et al. 2011). Esse fato é explicado, pois os herpesvírus bovinos possuem a capacidade de realizar latência após a infecção aguda, que pode ser reativada periodicamente, especialmente em situações de estresse como desmama, castrações, assinalação, vacinações, transporte, troca de pasto, introdução de novos animais no rebanho, mudanças bruscas na dieta ou tratamento com corticosteroides (Meyer et al. 2001, Colodel et al. 2002, Vogel et al. 2003, Elias et al. 2004, Lemos 2005, Barros et al. 2006, Halfen \& Riet-Correa 2007, Rissi et al. 2007). Esse fato demonstra a 
importância da associação dos achados anatomopatológicos e etiológicos nos casos de herpesvírus em geral, pois a detecção viral não necessariamente indica a doença, podendo sugerir latência do vírus. Em bovinos, o vírus pode permanecer em latência não só em gânglios de nervos sensoriais, mas também em córtex telencefálico, mesencéfalo, ponte, cerebelo e medula espinhal (Vogel et al. 2003). Mesmo com altos índices de letalidade, há relatos de animais doentes que se recuperaram completamente da enfermidade, espontaneamente ou após a administração de tiamina e corticosteroides (Riet-Correa et al. 1989, Salvador et al. 1998, Elias et al. 2004, Lemos 2005, Rissi et al. 2006).

As alterações macroscópicas observadas no encéfalo neste estudo foram muito semelhantes aos achados de outros autores (Colodel et al. 2002, Elias et al. 2004, Riet-Correa et al. 2006, Rissi \& Barros 2013). As alterações afetam geralmente todo o telencéfalo, mas, nos casos mais crônicos, elas são mais marcadas e graves na substância cinzenta do córtex frontal (Elias et al. 2004), podendo ser simétricas e bilaterais (Perez etal. 2002). Lesões semelhantes podem ser observadas no tálamo e núcleos basais (Elias et al. 2004, Rissi et al. 2006). Em cinco casos do presente estudo, não foram observadas lesões macroscópicas e, em quatro, não havia informações sobre qualquer alteração. Há relatos de meningoencefalite por BoHV sem lesões macroscópicas (Rissi et al. 2008). Isso provavelmente está relacionado a casos com curso clínico agudo, baixa neurovirulência ou susceptibilidade do animal, em que as lesões não se desenvolveram a ponto de serem observadas na necropsia, ou se desenvolveram a um ponto que, embora possíveis de serem observadas, são facilmente negligenciáveis (Rissi et al. 2006). 0 diagnóstico diferencial macroscópico com polioencefalomalacia de origem nutricional (Sant'Ana et al. 2009, Sant'Ana \& Barros 2010) pode ser feito com o auxílio de aplicação de luz ultravioleta sobre as áreas de malacia que não reagem nos casos de meningoencefalite por BoHV (Jackman \& Edwin 1983).

Os achados microscópicos são qualitativamente semelhantes aos descritos em várias publicações anteriores (Colodel et al. 2002, Elias et al. 2004, Riet-Correa et al. 2006, Rissi et al. 2006, Freitas Neto et al. 2010, Pedraza et al. 2010, Rissi \& Barros 2013, Oliveira et al. 2016). Em todos os casos, as alterações histológicas predominaram no córtex telencefálico, principalmente o córtex frontal e parietal, mas em alguns casos, lesões de menor intensidade foram também observadas no tálamo, núcleos basais, mesencéfalo, ponte, bulbo, cerebelo e hipocampo, semelhante aos achados de outros autores que também estudaram a distribuição das lesões no encéfalo (Salvador et al. 1998, Elias et al. 2004, Rissi et al. 2006). Em alguns casos, vasculite tem sido descrita na meningoencefalite por BoHV (Colodel et al. 2002, Lunardi et al. 2009), alteração essa não encontrada no presente estudo. Todos os animais apresentaram lesão inflamatória e corpúsculos de inclusão intranucleares basofílicos em astrócitos e/ou neurônios, porém há relatos da doença sem inflamação e/ou sem o corpúsculo de inclusão, podendo ser confundida com polioencefalomalacia nutricional (Ely et al. 1996, Colodel et al. 2002, Perez et al. 2002, Pedraza et al. 2010, Isernhagen et al. 2011, Oliveira et al. 2014). A não visualização de corpúsculos de inclusão foi associada a amostras autolisadas (Salvador et al. 1998) e previamente refrigeradas (Rissi et al. 2006). A presença e quantidade de corpúsculos de inclusão foram proporcionais as áreas de inflamação, gliose e malacia, corroborando com outros autores (Salvador et al. 1998, Rissi et al. 2006) e diferente de outros estudos (Elias et al. 2004). A localização das células gitter foi maior nas regiões superficiais dos telencéfalos, semelhante ao descrito por Salvador et al. (1998). Em seis casos desta investigação, os manguitos perivasculares continham alguns neutrófilos, sugerindo quadro agudo da doença, conforme visualizado em outros estudos (Salvador et al. 1998, Colodel et al. 2002, Elias et al. 2004, Rissi et al. 2006).

Um achado relevante nessa doença é a malacia, que foi observada em 13 casos. Essa lesão pode ser atribuída à isquemia secundária ao edema (Rissi et al. 2008), acometendo todas as regiões do encéfalo, principalmente o córtex frontal (Elias et al. 2004). Salvador et al. (1998) e Elias et al. (2004) observaram microscopicamente malacia em animais com evolução igual ou superior a três dias de infecção. No presente estudo, um caso apresentou infiltração de células gitter no mesencéfalo. Malacia em tronco encefálico foi observada em animais com reativação viral por polioencefalomalacia experimental causada por ingestão de sulfato de amônia (David et al. 2007) e em casos naturais de meningoencefalite herpética (Salvador et al. 1998, Elias et al. 2004). Lesão no tronco encefálico pode ser resultado da disseminação centrípeta viral via nervo trigêmeo (Perez et al. 2002).

Lesões atribuídas a BoHV não costumam ser observadas na medula espinhal, cerebelo e no gânglio trigêmio (Rissi et al. 2008, Oliveira et al. 2014, Cagnini et al. 2015). Neste estudo, não foi detectada nenhuma alteração no complexo GRH, porém alguns casos apresentaram lesões, geralmente inflamatórias, no cerebelo. Alguns autores citam que ausência de lesão no gânglio do nervo trigêmeo pode estar relacionada à via de infecção do vírus, geralmente por via olfatória (Rissi et al. 2006). Um caso apresentou necrose neuronal e edema perineuronal em neurônios de Purkinje, provavelmente secundário à compressão do telencéfalo com edema e isquemia sobre o cerebelo durante a herniação pelo forame magno. Esse achado foi semelhante ao descrito em outros relatos de infecção por BoHV (Salvador et al. 1998, Rissi et al. 2008) e em bovinos com polioencefalomalacia nutricional (Sant'Ana et al. 2009), porém Elias et al. (2004) observaram áreas de malacia na substância branca cerebelar sem lesões macroscópicas de edema telencefálico, sugerindo que essa lesão foi causada pelo próprio vírus.

A necrose neuronal e o edema (espongiose) corticais foram mais acentuados nas camadas granular externa, molecular, de células piramidais e granular interna. Achados similares foram identificados em casos de polioencefalomalacia nutricional em bovinos (Hamlen et al. 1993, Jeffrey et al. 1994, Sant'Ana et al. 2009). Em poucas investigações, a distribuição dessas lesões foi estudada em casos de meningoencefalite por BoHV. Salvador et al. (1998) observaram necrose cortical maciça, envolvendo todas as camadas corticais em casos de meningoencefalite por BoHV-5.

Quatro casos do presente estudo apresentaram astrócitos Alzheimer tipo II. Esses astrócitos são frequentemente encontrados no encéfalo em casos de encefalopatia hepática ou renal (Summers et al. 1995) e já foram relatados em animais com polioencefalomalacia nutricional (Sant'Ana et al. 2009). Embora nenhuma patogênese foi ainda proposta até o momento para a formação desses astrócitos na 
meningoencefalite herpética, na presente investigação, estes foram encontrados na substância cinzenta dos telencéfalos frontal e parietal associadas à necrose neuronal e espongiose do neurópilo. Sabe-se que essas células são mais resistentes que os neurônios a efeitos deletérios de neurotransmissores aminoácidos excitatórios em casos de necrose neuronal (Farooqui \& Horrocks 1991) e da amônia e outras toxinas na encefalopatia hepática (Norenberg 1987). A tumefação dessas células ocorre por acúmulo intracelular de ácido láctico e diminuição de pH intracelular (Staub et al. 1990).

Utilizou-se amostras congeladas de encéfalo de um bovino deste estudo para amplificação do DNA, com positividade para BoHV-1. Em tecido encefálico fixado em formol e incluído em parafina (FFIP) de 25 bovinos, apenas dois casos o DNA de BoHV-5 foi amplificado. Embora todos os casos fossem de infecção por BoHV, confirmados pela histopatologia, o tipo de vírus envolvido foi confirmado em $11,53 \%$ dos casos (3/26). Em casos naturais da doença, o DNA para BoHV-5 foi detectado em amostras FFIP, em 21,8\% (Ely et al. 1996), 28\% (Silva 2014), 33,3\% (Pedraza et al. 2010), 40\% (Arruda et al. 2010), 66,6\% (Gomes et al. 2002), 75\% (Ferrari et al. 2007) e 100\% (Cunha et al., 2009) dos casos. Em tecidos frescos e congelados, outros autores obtiveram 15,78\% (Gomes et al. 2002), 63,8\% (Claus et al. 2007), 66,66\% (Arruda et al. 2010) e $100 \%$ de extração (Ferrari et al. 2007, Lunardi et al. 2009, Massitel et al. 2016), utilizando PCR, PCR multiplex ou nested PCR. Experimentalmente o percentual aumentou, com 100\% de extração em parafina (Cagnini et al. 2015) e tecido fresco (Vogel et al. 2003, Isernhagen et al. 2011).

Bovinos com sinais neurológicos apresentaram mais lesões e maior porcentagem de áreas positivas para o BoHV em PCR e imuno-histoquímica (Cagnini et al. 2015). A maior concentração viral ocorreu no telencéfalos e no diencéfalo e, menos frequente, no cerebelo e bulbo em bovinos experimentalmente infectados (Isernhagen et al. 2011, Cagnini et al. 2015), reforçando a distribuição viral e a importância da análise dos telencéfalos para o diagnóstico da doença.

Em alguns estudos de casos brasileiros da doença, o DNA de BoHV-1 não foi amplificado utilizando-se amostras FFIP (Arruda et al. 2010, Silva 2014) e frescas de encéfalo (Claus et al. 2007, Lunardi et al. 2009). Embora haja indícios da circulação do BoHV-1 no Estado de Goiás por estudos sorológicos (Vieira et al. 2003, Barbosa et al. 2005, Affonso et al. 2010), os dados do presente trabalho sugerem que, pela primeira vez, no Centro-Oeste brasileiro, o BoHV-1 foi confirmado como causa de meningoencefalite viral. Entretanto, esse vírus já foi isolado em bovinos com meningoencefalite em outras regiões do Brasil, especialmente no Sul (Riet-Correa et al. 1989, Silva et al. 2007, Rissi et al. 2008, Rissi \& Barros 2013) e em outros países (Ely et al. 1996, Roels et al. 2000, Penny et al. 2002). Assim, ressalta-se a importância de diferenciar BoHV-5 e BoHV-1 por técnicas moleculares, como PCR, pois a doença clínica e as lesões causadas por esses agentes são muito semelhantes, senão idênticas (Lunardi et al. 2009).

0 tempo de permanência dos tecidos no formol $10 \%$ variou de acordo com a procedência da amostra, permanecendo entre dias até meses no fixador. Provavelmente, esse foi o principal fator responsável pela baixa porcentagem de casos positivos no PCR nas amostras emblocadas. Em outro estudo brasileiro, detectou-se $40 \%$ de positividade em amostras emblocadas sem tempo variável de permanência do tecido em formol 10\%, variando de dias até pouco mais de um ano, sendo afirmado que quanto maior o tempo do tecido no fixador, menor é a chance da detecção viral, principalmente por períodos maiores de 40 dias (Arruda et al. 2010). 0 percentual aumenta (75\%) na detecção de DNA viral por PCR em amostras que permaneceram apenas um dia (Ferrari et al. 2007), o que reforça que o tempo de fixação influencia acentuadamente na amplificação viral. Esses resultados podem ser explicados pela alteração da estrutura do DNA viral, desnaturação e modificação do mesmo em tecidos fixados pelo formaldeído (Karlsen et al. 1994). Resultados negativos em amostras emblocadas em parafina podem ser explicados também pela falha na extração de DNA, ausência ou baixa quantidade de DNA viral nas amostras (Arruda et al. 2010), o que provavelmente não aconteceu no presente estudo, visto que as técnicas moleculares utilizadas foram as mesmas utilizadas previamente (Arruda et al. 2010) e as lesões histológicas observadas são características de infecção pelo BoHV, incluindo corpúsculos de inclusão basofílicos intranucleares. Arruda et al. (2010) observaram um decréscimo de $50 \%$ na positividade para BoHV-5 por PCR em amostras incluídas em parafina em comparação as mesmas amostras testadas frescas e congeladas. A origem e qualidade do material (fresco ou bloco de parafina), distribuição do vírus na amostra, idade e raça dos animais, estágio da doença, severidade das lesões e o tempo até ser feita a necropsia podem comprometer e explicar a diferença entre a variação dos resultados de detecção viral por PCR (Ely et al. 1996, Ferrari et al. 2007, Cagnini et al. 2015).

Com base nos resultados obtidos nesse estudo e corroborando com outro autores (Ferrari et al. 2007), a utilização de amostras frescas para PCR apresenta resultados mais satisfatórios para extração de DNA em comparação com amostras FFIP. Mesmo com baixas porcentagens de extração viral, as amostras emblocadas em parafina permitem estudos retrospectivos de casos com doença neurológica, semelhante à metodologia aplicada nesse trabalho (Ely et al. 1996, Claus et al. 2005, Arruda et al. 2010, Silva 2014).

Quando se encontra resultados negativos na PCR e no isolamento viral, deve-se diferenciar a meningoencefalite herpética de outras afecções que cursam com quadro clínico neurológico, principalmente a polioencefalomalacia nutricional e a raiva (Sanches et al. 2000, Claus et al. 2007, Sant'Ana et al. 2009). No presente estudo, todos os casos foram negativos para raiva na imunofluorescência direita e, na microscopia, todos apresentaram corpúsculos de inclusão intranucleares em neurônios ou astrócitos, o que é importante na caracterização etiológica da doença e na diferenciação da polioencefalomalacia nutricional (Riet-Correa et al. 1989, Salvador et al. 1998, Elias et al. 2004, Rissi et al. 2006). Há relatos na literatura de infecção concomitante do BoHV-5 com o vírus da raiva, porém sem a confirmação exata se o BoHV-5 foi responsável pelas lesões detectadas ou se o BoHV-5 encontrava-se apenas em latência (Spilki et al. 2003, Silva 2014).

Agradecimentos.- Os autores agradecem ao LABVET/AGRODEFESA pelo fornecimento de muitas amostras utilizadas no presente estudo, bem como a Coordenação de Aperfeiçoamento de Pessoal de Nível Superior (CAPES) pelas bolsas de pós-graduação de dois autores (GRB, LFS) e ao Conselho Nacional de Desenvolvimento Científico e Tecnológico (CNPq) pelo apoio financeiro ao projeto (Processo 471837/2013-0) e pela bolsa de pós-graduação de um autor (JPT). 


\section{REFERÊNCIAS}

Affonso I.B., Amoril J.B., Alexandrino B., Buzinaro M.G., Medeiros A.S.R. \& Samara S.I. 2010. Anticorpos contra o herpesvírus bovino tipo 1 (BoHV-1) nas dez regiões de planejamento do estado de Goiás, Brasil. Ciênc. Anim. Bras. 11(4):892-898. http://dx.doi.org/10.5216/cab.v11i4.6318.

Aquino Neto H.M., Carvalho A.U., Facury Filho E.J., Ferreira P.M., BarbosaStancioli E.F., Lobato Z.I.P., Alvarenga M.R., Serrano A.L., Martins R.A. \& Afonso D.A.F. 2009. Meningoencefalite por Herpesvirus bovino 5 em Minas Gerais: relato de caso clínico. Arq. Bras. Med. Vet. Zootec. 61(1):1-5. http:// dx.doi.org/10.1590/S0102-09352009000100001.

Arruda L.P., Nakazato L., Dutra V., Lemos R.A.A., Nogueira A.P.A., Cruz R.A.S., Pescador C.A. \& Colodel E.M. 2010. Deteç̧ão molecular de herpesvírus bovino 1 e 5 em amostras de encéfalo conservadas em formol e emblocadas em parafina provenientes de bovinos com doença neurológica. Pesq. Vet. Bras. 30(8):646-650. http://dx.doi.org/10.1590/S0100-736X2010000800007.

Barbosa A.C.V.C., Brito W.M.E.D. \& Alfaia B.T. 2005. Soroprevalência e fatores de risco para a infecção pelo herpesvírus bovino tipo 1 (BHV-1) no Estado de Goiás, Brasil. Ciência Rural 35(6):1368-1373. http://dx.doi.org/10.1590/ S0103-84782005000600022.

Barros C.S.L. \& Marques G.H.F. 2003. Procedimentos para o diagnóstico das doenças do sistema nervoso central de bovinos. Depto Defesa Animal, Ministério da Agricultura, Pecuária e Abastecimento (MAPA), Brasília. 50p. Disponível em <http://www.agricultura.gov.br> Acesso em 30 mai. 2016.

Barros C.S.L., Driemeier D., Dutra I.S. \& Lemos R.A.A. 2006. Doenças do Sistema Nervoso de Bovinos no Brasil. Agnes, São Paulo, p.166-171.207p.

Cagnini D.Q., Cunha P.H.J., Pantoja J.C.F., Badial P.R., Oliveira-Filho J.P., Araújo-Junior J.P., Alfieri A.A. \& Borges A.S. 2015. Histopathological, immunohistochemical, and molecular study of BHV-5 infection in the central nervous system of experimentally infected calves. Pesq. Vet. Bras. 35(4):337-343. http://dx.doi.org/10.1590/S0100-736X2015000400004.

Claus M.P., Alfieri A.F., Folgueras-Flatschart A.V., Wosiacki S.R., Medici K.C. \& Alfieri A.A. 2005. Rapid detection and differentiation of bovine herpesvírus 1 and 5 glycoprotein $C$ gene in clinical specimens by multiplexPCR. J. Virol. Methods. 128(1-2):183-188. http://dx.doi.org/10.1016/j. jviromet.2005.05.001. PMid:15939490.

Claus M.P., Alfieri A.F., Médici K.C., Lunardi M. \& Alfieri A.A. 2007. Bovine herpesvirus 5 detection by virus isolation in cell culture and multiplex-pcr in central nervous system from cattle with neurological disease in Brazilian herds. Braz. J. Microbiol. 38(3):485-490. http://dx.doi.org/10.1590/ S1517-83822007000300019.

Colodel E.M., Nakazato L., Weiblen R., Mello R.M., Silva R.R.P., Souza M.A., Oliveira Filho J.A. \& Caron L. 2002. Meningoencefalite necrosante em bovinos causada por herpesvírus bovino no estado de Mato Groso do Sul, Brasil. Ciência Rural 32(2):293-298. http://dx.doi.org/10.1590/S010384782002000200018.

Cunha P.H.J., Delfiol D.J.Z., Cagnini D.Q., Badial P.R., Oliveira Filho J.P., Olivo G., Amorim R.M. \& Borges A.S. 2009. Identificação molecular do herpesvirus bovino tipo 5 em um bovino confinado associado com diagnóstico diferencial laboratorial de outras causas de polioencefalomalacia. Anais do VIII Congresso Brasileiro de Buiatria, Belo Horizonte, MG. Ciênc. Anim. Bras. (Supl. 1):93-98.

David N., Hübner S.O., Riet-Correa F., Halfen D. \& Lemos R.A.A. 2007. Reactivation of latent bovine herpesvirus type 5 in cattle with polioencephalomalacia induced by ammonium sulphate. Pesq. Vet. Bras. 27(10):435-441. http:// dx.doi.org/10.1590/S0100-736X2007001000009.

De Paula R.R., Souza M.A., Colodel E.M., Hübner S.O., Brum K.B., Jorge K.B.C. \& Damasceno A.D. 2005. Meningoencefalite causada pelo BHV-5 em um bovino no Estado de Goiás. Arq. Bras. Med. Vet. Zootec. 57(Supl. 1):2.

Elias F., Schild A.L. \& Riet-Correa F. 2004. Meningoencefalite e encefalomalacia por herpesvírus bovino-5: distribuição das lesões no sistema nervoso central de bovinos naturalmente infectados. Pesq. Vet. Bras. 24(3):123-131. http://dx.doi.org/10.1590/S0100-736X2004000300003.
Ely R.W., D’Offay J.M., Ruefer A.H. \& Cash C.Y. 1996. Bovine Herpesviral Encephalitis: A Retrospective Study on Archived Formalin-Fixed, ParaffinEmbedded Brain Tissue. J. Vet. Diagn. Invest. 8(4):487-492. http://dx.doi. org/10.1177/104063879600800416. PMid:8953538.

Farooqui A.A. \& Horrocks L.A. 1991. Excitatory amino acid receptors, neural membrane phospholipid metabolism and neurological disorders. Brain Res. Rev. 16(2):171-191. http://dx.doi.org/10.1016/0165-0173(91)90004-R. PMid:1662102.

Ferrari H.F., Luvizotto M.C.R., Rahal P. \& Cardoso T.C. 2007. Detection of bovine Herpesvirus type 5 in formalin-fixed, paraffin-embedded bovine brain by PCR: a useful adjunct to conventional tissue-based diagnostic test of bovine encephalitis. J. Virol. Methods 146(1-2):335-340. http://dx.doi. org/10.1016/j.jviromet.2007.07.018. PMid:17804088.

Franco A.C. \& Roehe P.M. 2007. Herpesviridae, p.433-488. In: Flores E.F. (Ed.), Virologia Veterinária. Editora UFSM, Santa Maria.

Freitas Neto A.P., Bannwart L.F., Verdejo A.C.F., Rabelo R.E., Garcia E.C. \& Sant'ana F.J.F. 2010. Meningoencefalite por herpesvírus bovino no Sudoeste de Goiás. Interbio 4(1):146.

Galiza G.J.N., Silva M.L.C.R., Dantas A.F.M., Simões S.V.D. \& Riet-Correa F. 2010. Doenças do sistema nervoso de bovinos no semiárido nordestino. Pesq. Vet. Bras. 30(3):267-276. http://dx.doi.org/10.1590/S0100736X2010000300014.

Gomes L.I., Rocha M.A., Costa E.A., Lobato Z.I.P., Mendes L.C.N., Borges A.S. Leite R.C. \& Barbosa-Stancioli E.F. 2002. Detecção de herpesvírus bovino 5 (BoHV-5) em bovinos do sudeste brasileiro. Arq. Bras. Med. Vet. Zootec. 54(2):217-220. http://dx.doi.org/10.1590/S0102-09352002000200014.

Halfen D.C. \& Riet-Correa F. 2007. Infecções por Herpesvírus Bovino-1 e Herpesvírus Bovino-5, p.126-137. In: Riet-Correa F., Schild A.L., Lemos R.A.A. \& Borges J.R.J. (Eds), Doenças de Ruminantes e Equídeos. Vol.1. $3^{\text {a }}$ ed. Pallotti, Santa Maria, 722p.

Hamlen H., Clark E. \& Janzen E. 1993. Polioencephalomalacia in cattle consuming water with elevated sodium sulfate levels: a herd investigation. Can. Vet. J. 34(3):153-158. PMid:17424182.

Isernhagen A.J., Cosenza M., Costa M.C.C., Médici K.C., Balarin M.R.S., Bracarense A.P.F.R.L., Alfieri A.A. \& Lisbôa J.A.N. 2011. Asymtomatic encephalitis in calves experimentally infected with bovine herpesvirus-5. Can. Vet. J. 52(12):1312-1318. PMid:22654135.

Jackman R. \& Edwin E.E. 1983. Cerebral autofluorescence and thiaminase deficiency in cerebrocortical necrosis. Vet. Rec. 112(23):548-550. http:// dx.doi.org/10.1136/vr.112.23.548. PMid:6879970.

Jeffrey M., Duff J.P., Higgins R.J., Simpson V.R., Jackman R., Jones T.O., Mechie S.C. \& Liversey C.T. 1994. Polioencephalomalacia associated with the ingestion of ammonium sulphate by sheep and cattle. Vet. Rec. 134(14):343-348. http://dx.doi.org/10.1136/vr.134.14.343. PMid:8017015.

Karlsen F., Kalantari M., Chitemerere M., Johansson B. \& Hagmar B. 1994. Modifications of human and viral deoxyribonucleic acid by formaldehyde fixation. Lab. Invest. 71(4):604-611. PMid:7967515.

Lemos R.A.A. 2005. Enfermidades do sistema nervoso de bovinos de corte das regiões Centro-Oeste e Sudeste do Brasil. Tese de Doutorado, Universidade Estadual Paulista, Jaboticabal, SP. 150p.

Lunardi M., Claus M.P., Lisbôa J.A.N., Amude A.M., Headley S.A., Alfieri A.F. \& Alfieri A.A. 2009. Neurological and epidemiological aspects of BoHV-5 meningoencephalitis outbreak. Braz. Arch. Biol. Technol. 52(spec.):77-85. http://dx.doi.org/10.1590/S1516-89132009000700011.

Massitel J.L., Wesgueber J., Oliveira R.A.M., Queiroz G.R., Fritzen J.T.T., Alfieri A.A. \& Lisbôa J.A.N. 2016. Presença do genoma de BoHV-5 no líquido cefalorraquidiano de bovinos com meningoencefalite herpética. Arq. Bras. Med. Vet. Zootec. 68(2):548-552. http://dx.doi.org/10.1590/1678-4162-8087.

Meyer G., Lemaire M., Ros C., Belak K., Gabriel A., Cassart D., Coignoul F., Belak S. \& Thiry E. 2001. Comparative pathogenesis of acute and latent infections 
of calves with bovine herpesvirus types 1 and 5. Arch. Virol. 146(4):633652. http://dx.doi.org/10.1007/s007050170136. PMid:11402854.

Norenberg M.D. 1987. The role of astrocytes in hepatic encephalopathy. Neurochem. Pathol. 6(1/2):13-33. http://dx.doi.org/10.1007/BF02833599. PMid:3306480.

Oliveira J.S., Albuquerque R.F., Aguiar-Filho C.R., Arruda L.P., Colodel E.M., Rocha B.P., Evêncio-Neto J. \& Mendonça F.S. 2014. Meningoencefalite necrosante em bovinos associada ao herpesvírus bovino-5 em Pernambuco, Brasil. Acta Scient. Vet. 42(supl. 1):43.

Oliveira T.S., Bull V., Furtini R., Drummnond S.R.M., Costa E.A., Santos R.L. \& Paixão T.A. 2016. Neurological diseases of cattle diagnosed through histopathology in Minas Gerais. Braz. J. Vet. Pathol. 9:62-69.

Pedraza F.J., Alessi A.C. \& Barbosa-Stancioli E.F. 2010. Detection of bovine herpesvirus 5 (BoHV-5) in formalin-fixed, paraffin-embedded bovine brain by nested PCR in Colombian cattle. Revta Colomb. Cienc. Pecuarias 23:292-298.

Penny C.D., Sargison N.D., Howie F., Nettleton P.F. \& Schock A. 2002. Upper respiratory disease and encephalitis in neonatal beef calves caused by bovine herpesvirus type 1. Vet. Rec. 151(3):89-91. http://dx.doi.org/10.1136/ vr.151.3.89. PMid:12164227.

Perez S.E., Bretschneider G., Leunda M.R., Osório F.A., Flores E.F. \& Odeón A.C. 2002. Primary infection, latency, and reactivation of Bovine Herpesvirus type 5 in the bovine nervous system. Vet. Pathol. 39(4):437-444. http:// dx.doi.org/10.1354/vp.39-4-437. PMid:12126146.

Riet-Correa F., Vidor T., Schild A.L. \& Méndez M.C. 1989. Meningoencefalite e necrose do córtex cerebral em bovinos causadas por Herpes Vírus Bovino-1. Pesq. Vet. Bras. 9:13-16.

Riet-Correa G., Duarte M.D., Barbosa J.D., Oliveira C.M.C., Cerqueira V.D., Brito M.F. \& Riet-Correa F. 2006. Meningoencefalite e polioencefalomalacia causada por Herpesvírus bovino-5 no Estado do Pará. Pesq. Vet. Bras. 26(1):44-46. http://dx.doi.org/10.1590/S0100-736X2006000100009.

Rissi D.R. \& Barros C.S. 2013. Necrotizing meningoencephalitis in a cow. Vet. Pathol. 50(5):926-929. http://dx.doi.org/10.1177/0300985813478209. PMid:23446433.

Rissi D.R., Oliveira F.N., Rech R.R., Pierezan F., Lemos R.A.A. \& Barros C.S.L. 2006. Epidemiologia, sinais clínicos e distribuição das lesões encefálicas em bovinos afetados por meningoencefalite por herpesvírus bovino-5. Pesq. Vet. Bras. 26(2):123-132. http://dx.doi.org/10.1590/S0100736X2006000200010.

Rissi D.R., Pierezan F., Silva M.S., Flores E.F. \& Barros C.S.L. 2008. Neurological disease in cattle in southern Brazil associated with Bovine herpesvirus infection. J. Vet. Diagn. Invest. 20(3):346-349. http://dx.doi. org/10.1177/104063870802000315. PMid:18460624.

Rissi D.R., Rech R.R., Flores E.F., Kommers G.D. \& Barros C.S.L. 2007. Meningoencefalite por herpesvírus bovino-5. Pesq. Vet. Bras. 27(7):251260. http://dx.doi.org/10.1590/S0100-736X2007000700001.
Roels S., Charlier G., Vanopdenbosch E., Letellier C., Kerkhofs P., Meyer G., Schynts F. \& Thiry E. 2000. Natural case of bovine herpesvirus 1 meningoencephalitis in an adult cow. Vet. Rec. 146(20):586-588. http:// dx.doi.org/10.1136/vr.146.20.586. PMid:10839237.

Roizmann B., Desrosiers R.C., Fleckenstein B., Lopez C., Minson A.C. \& Studdert M.J. 1992. The family Herpesviridae: an update. Arch. Virol. 123(3/4):425449. http://dx.doi.org/10.1007/BF01317276. PMid:1562239.

Salvador S.W.C., Lemos R.A.A., Riet-Correa F., Roehe P.M. \& Osório A.L.A.R. 1998. Meningoencefalite em bovinos causada por herpesvírus bovino-5 no Mato Grosso do Sul e São Paulo. Pesq. Vet. Bras. 18(2):76-83. http:// dx.doi.org/10.1590/S0100-736X1998000200007.

Sanches A.W.D., Langohr I.M., Stigger A.L. \& Barros C.S.L. 2000. Doenças do sistema nervoso central em bovinos no Sul do Brasil. Pesq. Vet. Bras. 20(3):113-118. http://dx.doi.org/10.1590/S0100-736X2000000300005.

Sant'Ana F.J.F. \& Barros C.S.L. 2010. Polioencephalomalacia in ruminants in Brazil. Braz. J. Vet. Pathol. 3:70-79.

Sant'Ana F.J.F., Rissi D.R., Lucena R.B., Lemos R.A.A., Nogueira A.P.A. \& Barros C.S.L. 2009. Polioencefalomalacia em bovinos: epidemiologia, sinais clínicos e distribuição das lesões no encéfalo. Pesq. Vet. Bras. 29(7):487-497. http:// dx.doi.org/10.1590/S0100-736X2009000700002.

Silva D.R. 2014. Detecção molecular de herpesvírus bovino tipo-1 e herpesvírus bovino tipo-5 em amostras de encéfalos bovinos incluídos em parafina. Tese de Mestrado. Universidade Federal de Goiás, Goiânia, GO. 48p.

Silva M.S., Brum M.C.S., Weiblen R. \& Flores E.F. 2007. Identificação e diferenciação de bovino tipos 1 e 5 isolados de amostras clínicas no Centro-Sul do Brasil, Argentina e Uruguai (1987-2006). Pesq. Vet. Bras. 27(10):403-408. http://dx.doi.org/10.1590/S0100-736X2007001000003.

Spilki F.R., Franco A.C., Teixeira M.B., Esteves P.A., Schaefer R., Schmidt E., Lemos R.A. \& Roehe P.M. 2003. Bovine herpesvirus type 5 (BHV-5) in a calf with rabies. Pesq. Vet. Bras. 23(1):1-4. http://dx.doi.org/10.1590/ S0100-736X2003000100001.

Staub F., Baethmann A., Peters J., Weigt H. \& Kempski O. 1990. Effects of lactacidosis on glial cell volume and viability. J. Cereb. Blood Flow Metab. 10(6):866-876. https://doi.org/10.1038/jcbfm.1990.143. PMID: 2211880.

Summers B.A., Cummings J.F. \& De Lahunta A. 1995. Veterinary neuropathology, Mosby, St Louis. 527p.

Vieira S., Brito W.M.E.D., Souza W.J., Alfaia B.T. \& Linhares C.L. 2003. Anticorpos para o herpesvírus bovino 1 (BHV-1) em bovinos do Estado de Goiás. Ciênc. Anim. Bras. 4:131-137.

Vogel F.S.F., Caron L., Flores E.F., Weiblen R., Winkelmann E.R., Mayer S.V. \& Bastos R.G. 2003. Distribution of bovine herpesvirus type 5 DNA in the central nervous systems of latently, experimentally infected calves. J. Clin. Microbiol. 41(10):4512-4520. http://dx.doi.org/10.1128/JCM.41.10.45124520.2003. PMid:14532175. 